\title{
Process Performance and Kinetic Characteristic of Anaerobic Digestion Focusing on Swine Manure Content
}

\author{
Chun-lan MAO \\ The Research Center of Recycle Agricultural Engineering \\ and Technology \\ College of Forestry, Northwest A\&F University \\ Shaanxi Province, Yangling, China \\ e-mail: gmc11128@163.com

\section{Yong-zhong FENG*} \\ The Research Center of Recycle Agricultural Engineering \\ and Technology \\ College of Agronomy, Northwest A\&F University \\ Shaanxi Province, Yangling, China \\ e-mail: fengyz@nwsuaf.edu.cn
}

\author{
Xiao-jiao WANG \\ The Research Center of Recycle Agricultural Engineering \\ and Technology \\ College of Agronomy, Northwest A\&F University \\ Shaanxi Province, Yangling, China \\ e-mail:w-xj@nwsuaf.edu.cn
}

\begin{abstract}
This study investigated the process performance and kinetics of mono-, and co-digestion of swine manure and corn straw focusing on swine manure content in the total substrate. Batch anaerobic digestion tests were conducted at mesophilic condition. First-order model and Logistic model were used to assess the effect of swine manure content on degradation efficiency, biogas production rate and lag phase and predict biogas production potential. The results indicated that process stability and biogas production, degradation efficiency and biogas production rate increased while lag phase time decreased with the increase of swine manure content. Additionally, swine manure content of R4 showed the best $\mathrm{AD}$ performance, and according to the analyzed results and kinetic analysis, it suggested that the appropriate value of swine manure content might be $70 \%$.
\end{abstract}

Keywords-anaerobic digestion; swine manure; corn straw; correlation; kinetics

\section{INTRODUCTION}

Substantive investigations have been conducted on the anaerobic digestion (AD) of swine manure mainly centered on analyses of process performance, microbial community shift and kinetics under different operational conditions, using mono-digestion or co-digestion of swine manure [1, 2]. Factors affecting degradation efficiency, process stability and biogas production include $\mathrm{pH}$, temperature, organic loading rate, mixed ratio [3-5], and some inhibitory factors of $\mathrm{AD}$ byproducts, including ammonia nitrogen and VFAs are also studied. In addition, pretreatment is a promising method to improve $\mathrm{AD}$ efficiency, especially in co-digestion of swine and crop straw. Moreover, researches about kinetics of mono-digestion and co-digestion swine manure focused on ADM1-based modelling, first-order models, Transfer function model, Cone models [6] and modified Gompertz model [7]. However, use of model mainly depends on operational conditions.

However, no previous study has investigated the influence of swine manure content on process performance and kinetics in $\mathrm{AD}$ of swine manure, or focused on the detailed correlation analyses of parameters. Hence, in order to achieve a comprehensive understanding of process performance and mechanism of parameter interacting during $\mathrm{AD}$ process of mono-, and co-digestion of swine manure with corn straw, particularly aim on demonstrating the correlation between kinetics and substrate characteristic and providing theoretical basis for further study, the objectives of the present study was to investigate the correlation between biogas production and process parameters, influence of substrate characteristic on kinetic parameters, hydrolysis rate. The predicted biogas potential was also showed.

\section{MATERIALS AND METHODS}

\section{A. Substrates and Inoculum}

Air-dried corn straw crushed into 2- to 3-mm pieces, fresh swine maure and inoculum produced from a household mesophilic anaerobic reactor were collected from a local village in Yangling, China. The physicochemical properties of feedstocks were analyzed (Table 1). 
TABLE 1. CHEMICAL CHARACTERTZATION OF SUBSTRATES USED IN THE DIGESTERS

\section{RESULTS AND DISCUSSION}

\section{A. Biogas Production}

Variation of daily biogas production and accumulative

\begin{tabular}{cccccc}
\hline & $\begin{array}{c}\mathrm{TS}^{\mathrm{a}} \\
(\%)\end{array}$ & $\begin{array}{c}\mathrm{VS}^{\mathrm{a}} \\
(\%)\end{array}$ & $\begin{array}{c}\mathrm{TOC}^{\mathrm{a}} \\
(\mathrm{g} / \mathrm{kg} \mathrm{VS})\end{array}$ & $\mathrm{C} / \mathrm{N}$ & $\mathrm{pH}$ \\
\hline $\mathrm{SM}$ & $53.58 \pm 3.31$ & $84.45 \pm 4.66$ & $26.66 \pm 1.13$ & $17.85 \pm 0.21$ & $6.4 \pm 0.12$ \\
$\mathrm{CS}$ & $96.55 \pm 6.34$ & $90.66 \pm 5.56$ & $46.5 \pm 2.17$ & $82.3 \pm 1.51$ & $\mathrm{ND}^{\mathrm{b}}$ \\
Inoculum & $6.59 \pm 1.51$ & $75.4 \pm 4.12$ & $\mathrm{ND}^{\mathrm{b}}$ & $\mathrm{ND}^{\mathrm{b}}$ & $8.4 \pm 0.18$ \\
\hline
\end{tabular}

Note: a, Dry basis; b, Not determined

SW: swine manure; CS: corn straw; TOC: total organic carbon

\section{B. Anaerobic Digestion}

Laboratory-scale batch anaerobic digestion was conducted at mesophilic condition $\left(37 \pm 1^{\circ} \mathrm{C}\right)$ in $1 \mathrm{~L}$ glass bottles with a $700 \mathrm{~mL}$ working volume. Each digester had a TS content of $8 \%$ and a substrate to inoculum ratio $(\mathrm{S} / \mathrm{I})$ of 2.5:1. Five experimental treatments were set: R1 (mono-digestion of corn straw, no swine manure was added), R2, R3, R4 (co-digestion with swine manure content of $30 \%, 50 \%$ and $70 \%$ (TS basis), respectively), R5 (mono-digestion of swine manure, no corn straw was added).

\section{Kinetic Study}

First-order model (Eq. (1)) [6] has been widely used in previous studies when the hydrolysis reaction was the rate-limiting step of anaerobic digestion process. It was used to predict methane yield from anaerobic digestion [6, 8]. In this study, a first-order model was used to describe the hydrolysis rate of different anaerobic digestion phases. It showed a straight line with a slope whose magnitude is the hydrolysis rate constant.

$$
M_{(t)}=M_{\max } \cdot[1-\exp (-k t)]
$$

Where $M_{(t)}$ is the accumulative biogas production $\left(\mathrm{mLg}^{-1} \mathrm{VS}\right)$ at an anaerobic digestion time $\mathrm{t}(\mathrm{d}), M_{(\max )}$ is the maximum accumulative biogas production at the end of anaerobic digestion process, and $k$ is the observed hydrolysis constant $\left(\mathrm{d}^{-1}\right)$. The value of $k$ was estimated by a linear regression fit.

A Logistic model (Eq. (2)) were used to fit the accumulative biogas production data obtained from experiments. The model was used when an inhibitory phenomenon was observed in the anaerobic digestion process and assumed that the methane production reflects the bacterial growth.

$$
M_{(\mathrm{s})}=\frac{B_{\max }}{1+\exp \left(\frac{4 \pi}{E}(\lambda-2)+2\right)}
$$

$M_{(t)}$ is the accumulative biogas production $\left(\mathrm{mLg}^{-1} \mathrm{VS}\right)$ at an AD time $t(\mathrm{~d}), P_{\max }$ is biogas production potential ( $\left.\mathrm{mLg}^{-1} \mathrm{VS}\right), R$ is the maximum biogas production rate $\left(\mathrm{mLg}^{-1} \mathrm{VSd}^{-1}\right)$, and $\lambda$ is the lag-phase time $(\mathrm{d})$. The values of $P_{\max }, R$ and $\lambda$ were estimated by a non-liner program. SPASS Statistics 20 was used for the analysis of standard deviations and significance of differences and linear and non-liner fitting of models. biogas production of all treatments was shown in Fig.1. Compared with the peak value of each treatment, it found that R1, R2 had one obvious peak value at 19d. R3, R4 had two obvious peaks and the first peak was achieved at $3 \mathrm{~d}$ and the second peak was achieved at $10 \mathrm{~d}$ and $8 \mathrm{~d}$, respectively (Fig.1a). R5 reached the main peak at 5d. Therefore, starting-up time significantly reduced with the increasing of swine manure content which could be indicated by the time of peak value appeared. These peak values increased from with the rising of swine manure content, ranged from $14.19 \mathrm{mLg}^{-1} \mathrm{VSd}^{-1}$ for $\mathrm{R} 2$ to $26.28 \mathrm{mLg}^{-1} \mathrm{VSd}^{-1}$ for $\mathrm{R} 5$. Although R1 had a higher peak value of $19.06 \mathrm{mLg}^{-1} \mathrm{VSd}^{-1}$ than R2, it showed a longer lag phase and then rapidly decreased and maintain a lower level which could due to the high $\mathrm{C} / \mathrm{N}$ ratio in $\mathrm{R} 1$. In $\mathrm{R} 5$, the biogas production rate showed a "sharply rose-declined" tendency with the shortest lag time. Therefore, accumulative biogas production of R5 showed a rapid rising tendency at initial stage of 16 days followed by R4 (Fig.1b). However, though $\mathrm{R} 5$ achieved the highest biogas production rate, $\mathrm{R} 4$ obtained the highest accumulative biogas production of $434.9 \mathrm{mLg}^{-1} \mathrm{VS}$, with an increase of $69.8 \%, 32.4 \%, 22.5 \%$ and $25.4 \%$ than R1, R2, R3 and R5. These could be explained that higher swine manure content in corn straw provides a suitable $\mathrm{C} / \mathrm{N}$ ratio which is important for $\mathrm{AD}$ stability. Furthermore, degradation efficiency could be increased by more easily degradable matters in swine manure and decrease the duration time of AD. Moreover, complex composition of substrate in co-digester contributes to the system stability than mono-digestion of swine manure and corn straw.

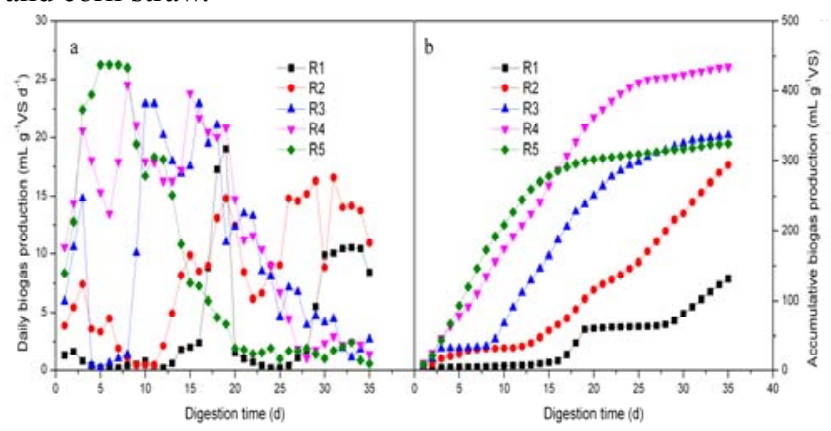

Figure 1 Variation of biogas production during AD process in the digesters

\section{B. Influence of Process Parameters on Methane Yield}

$\mathrm{AD}$ process is generally divided into four stages, i.e. hydrolysis, acidogenesis, acetogenesis and methanogenesis. Each stage includes material metabolism and energy transformation depending on microbial activity. The synergistic effect of process parameters, such as $\mathrm{pH}$, VFA, ammonia nitrogen (AN) and alkalinity (AL) influences the microbial activity, consequently definitely affects methane production. As shown in Table 2, there was a significantly correlation between these parameters and methane. It found 
that $\mathrm{pH}$ significantly promotes methane production $(\mathrm{P}<0.01)$, while VFA shows a negative correlation to methane production with no significant $(\mathrm{P}>0.05), \mathrm{AN}$ and AL effect methane production positively without significant $(\mathrm{P}>0.05)$. It is well known that buffer system do not form in the first few days, a decrease in $\mathrm{pH}$ is observed due to the generation of VFA (significantly negative correlation, $\mathbf{P}<0.01$ ). However, higher VFA concentration might stimulate more AL due to the buffer system. Therefore, a significant positive correlation $(\mathrm{P}<0.01)$ between VFA and $\mathrm{AL}$ and a negative correlation between $\mathrm{pH}$ and $\mathrm{AL}(\mathrm{P}<0.05)$ were observed. Furthermore, AN is the only nitrogen nutrient for methanogens during AD process. Along with the AD process, AN was constantly consumed and methanogens activity was improved which accelerated the availability of VFA and $\mathrm{pH}$ was increased. As a result, methane production was improved. For R1 and R2, higher carbon content resulted in VFA accumulation and much lag time than other treatments. For R4, complex nutrient

TABLE 2. CORRELATION ANALYSIS BETWEEN METHANE YIELD AND PROCESS PARAMETERS IN THE DIGESTERS

\begin{tabular}{lllllll}
\hline & & MY & pH & VFA & AN & AL \\
\hline MY & Pearson & 1 & $.678^{* *}$ & -.316 & .115 & .173 \\
& Correlation & & & & & \\
& Sig. (2-tailed) & & .000 & .064 & .509 & .320 \\
& N & 35 & 35 & 35 & 35 & 35 \\
$\mathrm{pH}$ & Pearson & $.678^{* *}$ & 1 & $-.704^{* *}$ & $.343^{*}$ & -.425 \\
& Correlation & & & & & ${ }^{*}$ \\
& Sig. (2-tailed) & .000 & & .000 & .043 & .011 \\
& N & 35 & 35 & 35 & 35 & 35 \\
VFA & Pearson & -.316 & $-.704^{* *}$ & 1 & -.257 & $.455^{*}$ \\
& Correlation & & & & & $*$ \\
& Sig. (2-tailed) & .064 & .000 & & .136 & .006 \\
& N & 35 & 35 & 35 & 35 & 35 \\
AN & Pearson & .115 & $.343^{*}$ & -.257 & 1 & -.022 \\
& Correlation & & & & & \\
& Sig. (2-tailed) & .509 & .043 & .136 & & .899 \\
& N & 35 & 35 & 35 & 35 & 35 \\
AL & Pearson & .173 & $-.425^{*}$ & $.455^{* *}$ & -.022 & \\
& Correlation & & & & & \\
& Sig. (2-tailed) & .320 & .011 & .006 & .899 & 1 \\
& N & 35 & 35 & 35 & 35 & 35
\end{tabular}

**. Correlation is significant at the 0.01 level (2-tailed).

*. Correlation is significant at the 0.05 level (2-tailed).

structure improved the stability of AD system.

\section{Kinetics Analysis}

Two kinetics results obtained from first-order model and Logistic model were shown as in Table 3. It demonstrates a strong fit between AD process in batch tests and the two models with the $\mathrm{R}^{2}$ ranges of $0.700-0.945$ and $0.942-0.997$ respectively.

$\mathrm{k}$ is representing the hydrolysis rate and high values represent fast degradation and biogas production. As for $\mathrm{k}$ values, high swine manure content in co-digestion system showed higher $\mathrm{k}$ values and increasing swine manure content caused an increased degradation and biogas production, compared to the lower swine manure content in AD system when swine manure content higher than R2. In addition, in the initial stage (Fig.1a), high degradation efficiency was accelerated by the increase of swine manure, thus, $\mathrm{k}$ of substrate exhibits a rising trend at increasing contribution of swine manure.

Lag phase duration $(\lambda)$ is a phenomenon inherent to microbial kinetics and is regarded as a delayed response of the microbial population to the environment change. In the present study, compared with the $\lambda$ values of each treatment, the shortest lag phase (1.70d) was observed at the R5 and the longest lag phase (13.65d) for R1 was observed while others falling between these two values and demonstrating an decreasing along with the increasing of swine manure content. The variation of $\lambda$ values presented opposite tendency of $\mathrm{k}$. Hence, it could be speculated that higher swine manure content would have a positive effect on the hydrolysis and acidogenesis of organics, thus enhancing the buffer capacity of $\mathrm{AD}$ system and causing shorter lag phases.

$R$ values demonstrate the biological reaction rate and describe methanogenic activity, which showed similar tendency with $\mathrm{k}$ with the increase of swine manure content. The $R$ values of all treatments ranged from $6.09-25.41 \mathrm{mLg}^{-1} \mathrm{VSd}^{-1}$, and the higher $R$ values were achieved at the higher swine manure content. For example, the $R$ value in $\mathrm{R} 5$ was $25.41 \mathrm{mLg}^{-1} \mathrm{VSd}^{-1}$ followed by R4 of $21.98 \mathrm{mLg}^{-1} \mathrm{VSd}^{-1}, \quad 24.4 \%, \quad 44.3 \%$ and $76 \%$ higher respectively compared with R3, R2 and R1. Based on the above analysis, the variation of $\mathrm{R}$ with different swine manure content could be due to the difference in substrate component and microbial activity and hydrolysis rates during AD process. $P_{\max }$ values exert similar tendency with accumulative biogas production.

TABLE 3. RESULTS OF PARAMETERS OBTAINED FROM FIRST-ORDER MODEL AND LOGISTIC MODEL

\begin{tabular}{cccccccc}
\hline \multirow{2}{*}{ Items } & \multicolumn{2}{c}{ First-order model } & & \multicolumn{4}{c}{ Logistic model } \\
\cline { 2 - 3 } \cline { 5 - 7 } & $\mathrm{k}$ & $\mathrm{R}^{2}$ & & $P_{\max }$ & $R$ & $\lambda$ & $\mathrm{R}^{2}$ \\
\hline $\mathrm{R} 1$ & 0.0519 & 0.700 & & 139.47 & 6.09 & 13.65 & 0.942 \\
$\mathrm{R} 2$ & 0.0659 & 0.717 & & 313.15 & 14.16 & 12.70 & 0.994 \\
$\mathrm{R} 3$ & 0.1358 & 0.899 & & 350.45 & 19.22 & 5.76 & 0.997 \\
$\mathrm{R} 4$ & 0.1513 & 0.943 & & 437.30 & 21.98 & 2.27 & 0.997 \\
$\mathrm{R} 5$ & 0.1528 & 0.945 & & 324.64 & 25.41 & 1.70 & 0.993 \\
\hline
\end{tabular}

In addition, the correlation relationship between kinetic parameters obtained from first order model and Logistic model and VS concentration in the total substrate was analyzed and the results were presented in Fig. 2.

As for $\mathrm{k}$, the values decreased quadraticly with VS (Fig. 2a) and $P_{\max }$ values showed similar trend with k (Fig. 2b). As to $R$, it decreased linearly with VS (Fig. 2c), which indicated that high VS concentration would inhibit the digestion process thus influencing the biogas production. For $\lambda$ value, it increased exponentially with VS. These relationships indicated that high VS concentration would have a major adverse impact on anaerobic co-digestion performance of swine manure and corn straw and may influence biogas production and alter the stabilization of methanogenesis processes. As shown in Fig. 2, with increased VS concentration in the substrate, the lag phase $(\lambda)$ was prolonged and the biogas potential $\left(P_{\max }\right), R$ and $\mathrm{k}$ were decreased. 


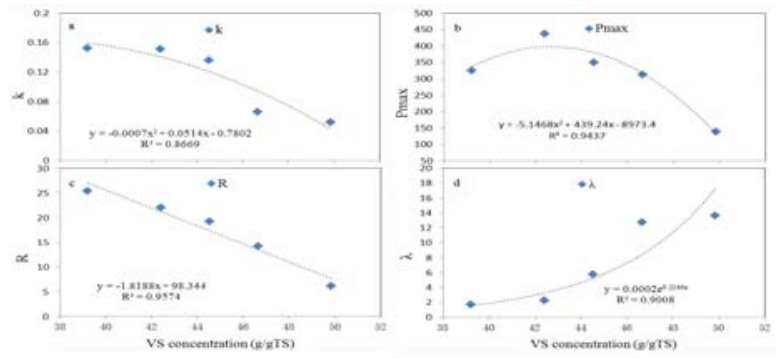

Figure 2 Correlation analysis between VS concentration and parameters obtained from first-order model and Logistic model

\section{CONCLUSIONS}

This study studied the process performance and kinetics of mono-digestion and co-digestion of swine manure and corn straw and analyzed the relationship between biogas production and process parameters, effect of swine manure content on kinetic parameters. The results showed that R1 and R2 presented lower organics degradation efficiency, biogas production and hydrolysis rate and longer lag phase duration due to the inhibition of the organics bioconversion cause by rich lignocellulose. Based on the analyzed results obtained in this study, it can be concluded that swine manure content is recommended up $70 \%$ in the co-digestion of corn straw causing not only a shorter lag phase duration and $\mathrm{AD}$ period, but also higher hydrolysis rate and biogas yield.

\section{ACKNOWLEDRMENTS}

This work was supported by Science and Technology Innovation Project Plan of Shaanxi Province (2015KTCL02-07) and Integrated Renewable Biomass Energy Development Project: Numbers Assignment for Consulting Services of Special Study on Key Technology and Implementation Standards of Applying Biogas Fertilizer on Crops (GEF: Grant 0203-PRC).

\section{REFERENCES}

[1] Zhou J, Zhang R, Liu F, Yong X, Wu X, Zheng T, et al. Biogas production and microbial community shift through neutral $\mathrm{pH}$ control during the anaerobic digestion of pig manure. Bioresource technology. 2016;217:44-9.

[2] Zhou S, Nikolausz M, Zhang J, Riya S, Terada A, Hosomi M. Variation of the microbial community in thermophilic anaerobic digestion of pig manure mixed with different ratios of rice straw. Journal of bioscience and bioengineering. 2016;122:334-40.

[3] Piatek M, Lisowski A, Kasprzycka A, Lisowska B. The dynamics of an anaerobic digestion of crop substrates with an unfavourable carbon to nitrogen ratio. Bioresource technology. 2016;216:607-12.

[4] Deng L, Chen C, Zheng D, Yang H, Liu Y, Chen Z. Effect of temperature on continuous dry fermentation of swine manure. Journal of environmental management. 2016;177:247-52.

[5] E. Jurado GA, G. Lyberatos, H.N. Gavala, I.V. Skiadas Continuous anaerobic digestion of swine manure: ADM1-based modelling and effect of addition of swine manure fibers pretreated with aqueous ammonia soaking. Applied Energy. 2016:190-8.

[6] Li K, Liu R, Sun C. Comparison of anaerobic digestion characteristics and kinetics of four livestock manures with different substrate concentrations. Bioresource technology. 2015;198:133-40.

[7] Zhang W, Wei Q, Wu S, Qi D, Li W, Zuo Z, et al. Batch anaerobic co-digestion of pig manure with dewatered sewage sludge under mesophilic conditions. Applied Energy. 2014;128:175-83.

[8] Zhen G, Lu X, Kobayashi T, Li Y-Y, Xu K, Zhao Y. Mesophilic anaerobic co-digestion of waste activated sludge and Egeria densa: Performance assessment and kinetic analysis. Applied Energy. 2015;148:78-86. 